\title{
La Sociedad Nezahualcóyotl: evidencias de una generación literaria decimonónica
}

\author{
Leticia Romero Chumacero \\ Universidad Autónoma de la Ciudad de México
}

Resumen

La Sociedad Nezahualcóyotl se instauró en la ciudad de México en 1868. Inició como un proyecto poético de coyuntura, pero sus integrantes pronto fueron identificados como parte de una generación literaria nueva, hermanada por un programa estético y un ideario político que coincidían con los de la facción vencedora tras la guerra de Reforma. Tal agrupación literaria, sin embargo, no logró desarrollarse plenamente debido a la temprana muerte de algunos y el distanciamiento de quienes optaron por la política como profesión. El presente artículo propone un esbozo a través del cual, pese a la pronta disgregación del grupo referido, se confirma lo aseverado por su principal mentor: aquella Sociedad era una expresión diáfana de la Generación de 1867.

Palabras clave: literatura, México, siglo XIX, generación literaria, nacionalismo.

\section{Abstract}

The Sociedad Nezahualcóyotl was established in Mexico City in 1868. It began as a poetic project, but its members were soon identified as part of a new literary generation, twinned by an aesthetic program and political ideology. Such literary group, however, failed 
to develop fully because of the early death of some and the alienation of those who chose politics as a profession. This paper we confirms the assertions of his main mentor, Ignacio Manuel Altamirano: The Sociedad Nezahualcóyotl was an expression of Generation to 1867.

Keywords: Literature, Mexico, Nineteenth Century, Literary Generation, Nationalism.

\section{Forjar una literatura propia}

Omienza a oscurecer pero la tarde aún es tibia cuando el buConvento de San Jerónimo. Son observados con poco interés por los miembros de la brigada que ocupó el recinto desde el año anterior, 1867, inmediatamente después de que las monjas fueron exclaustradas. A la pequeña tropa apostada en los claustros aledaños no le sorprende en demasía el ruidoso arribo de aquellos estudiantes, pues desde que fue decretado el desalojo de los conventos, mucha gente penetra en éstos con curiosidad, en pos de los secretos guardados por las religiosas durante siglos de encierro elegido. Pero los estudiantes tienen en mente sólo a una de las mujeres que vistieron el hábito de las jerónimas; a esa monja le rendirán homenaje durante sus reuniones a partir de esa tarde porque, igual que ellos, sor Juana Inés de la Cruz fue poeta.

Únicamente algunos en el grupo formado por Manuel Acuña, Agustín F. Cuenca, Francisco G. Cosmes, Alfredo Higareda, Francisco Ortiz, Miguel Portillo, Rafael Rebollar, Javier Santa María, Pablo Sandoval y Gerardo M. Silva, superan los quince años de edad; ninguno llega a veinte. Ese día, 24 de abril de 1868, bajo los árboles del jardín de San Jerónimo instalan la Sociedad Nezahualcóyotl, convencidos de la importancia de buscar una literatura propia, reformar el teatro e impulsar las publicaciones literarias (Cuenca, 1874: 11-14); persuadidos de que pueden hacerlo. Para 
ello cuentan con el estímulo y padrinazgo de Ignacio Manuel Altamirano, quien sigue con detenimiento el desarrollo de sus carreras literarias y ha prometido abrirles las puertas de la prestigiosa revista El Renacimiento para que den a conocer algunas primicias. Precisamente ahí les da la bienvenida unos meses más tarde:

Esta sociedad [Nezahualcóyotl] se compone de jóvenes estudiantes, laboriosos y entusiastas, que no desmayan, y que acabarán por franquear las cumbres de la fama, sólo accesibles a aquellos que tienen fe y que no se cansan. Cuando sean conocidas en México la perseverancia, la actividad y la decisión con que los jóvenes [...] se han consagrado a sus tareas, luchando con todos los obstáculos que puede amontonar la pobreza, la escasez de libros y la falta de protección, estamos seguros de que se les admirará y se les concederá un voto de profunda simpatía (Altamirano, 1979a: 19).

Otro muchacho, Juan de Dios Peza, se unirá al grupo apenas supere el amargo trago de ver partir a su padre, ministro de Guerra de Maximiliano de Habsburgo, hacia el destierro. Y será precisamente Peza quien cerca de su cumpleaños número sesenta, escriba nostálgicos y memoriosos artículos sobre las ilustres reuniones protagonizadas por él y su grupo de amigos de juventud. En una de ellas hablará de un encuentro celebrado a mediados de 1872, en el número 13 del primer piso del segundo patio de la Escuela de Medicina - donde estudiaron varios, donde se suicidó el más famoso. Dirá que juntos bebieron café, "el néctar negro de los sueños blancos", con sus gotas de aguardiente catalán, "el néctar blanco de los sueños negros" (Peza, 1894: 76). Recordará que en esa ocasión improvisaron versos y ocurrencias sobre un cráneo que alguien, divertido, introdujo en la habitación del saltillense Acuña, poeta y aspirante a médico.

Peza y sus camaradas se articulaban en torno de intereses estéticos propios del romanticismo y alrededor de intereses políticos atra- 
vesados por el liberalismo; compartían una formación académica marcada por el positivismo recién llegado al país y divulgado desde la Escuela Nacional Preparatoria, así como una geografía estudiantil y laboral netamente capitalina. Los unían también sus relaciones con cierto grupo de mentores (Ignacio Manuel Altamirano, Ignacio Ramírez, Guillermo Prieto) y con sus publicaciones periódicas. Altamirano los identificó en su momento como parte de la "nueva generación literaria": "aquella que ha hecho su aparición o ha publicado sus obras después de 1867” (2002: 22). Cabría distinguirla como una "generación típica" (Curiel, 2008: 288), es decir, constituida por coetáneos, que operó básicamente dentro de la constelación nacionalista (integrada por coetáneos y contemporáneos) vigente durante el Segundo Imperio y la República Restaurada. En suma, a casi ciento cincuenta años de distancia de las reuniones efectuadas en algún patio del Ex convento de San Jerónimo de la ciudad de México, es posible confirmar lo establecido por Altamirano: los protagonistas de aquellas tertulias juveniles formaron parte de una generación, porque amén de cercanía en materia de edad, compartieron una "consanguinidad espiritual pautada por semejanzas y diferencias" (Curiel, 2008: 169). Es importante establecer desde ahora que la bautizada por Altamirano como Generación de 1867, también ha sido llamada Generación de los Científicos (González y González, 1984: 37-51) y Generación del Renacimiento (Tola de Habich, 2005: 216). En el primer caso, el énfasis nominal está puesto en el origen: la fecha del triunfo liberal y su promesa de transformación nacional; 1867 era, para usar un término caro al Maestro, el ańo del renacimiento del país, después de varias décadas de guerra. En el segundo caso, la denominación destaca uno de los grupos dominantes del gabinete porfiriano al finalizar el siglo, el de los Científicos, así como su credo, el positivista. Para el tercer nombre, Fernando Tola de Habich acudió al de 
la publicación más representativa del nacionalismo conciliatorio: El Renacimiento, en circulación durante 1867.

Aquella generación, pues, debe concebirse como un universo amplio capaz de circunscribir a muchos de los intelectuales, políticos, artistas y demás integrantes del grupo de notables que presidieron el país durante buena parte del último cuarto del siglo XIX. Con ese conjunto de personas, la Sociedad Nezahualcóyotl compartió una "consanguinidad espiritual" susceptible de clasificación a partir de algunos ejes torales: sus miembros, jóvenes de la posguerra, se mostraron interesados en participar en la reconstrucción del país suscribiendo el programa literario nacionalista y laico de sus mentores y participando en tareas de carácter público (política, diplomacia, academia, periodismo), de ahí que su declive haya llegado, con lentitud, a la par de dos revoluciones: una estética y una política. Veamos.

\section{Tras la guerra, vigorizar la literatura nacional}

Los muchachos que rindieron homenaje a sor Juana Inés de la Cruz en 1868 compartían un país que recién había optado por la república como forma de gobierno y por el positivismo como filosofía económica y orientación pedagógica; esta última, expresada en la Ley de Instrucción Pública redactada a petición del presidente Benito Juárez, por el poblano Gabino Barreda, discípulo de Auguste Comte. Algunos de los fundadores de la Sociedad, como Agustín F. Cuenca o Gerardo M. Silva, cursaron sus estudios en el Colegio Nacional de San Ildefonso — aún en manos de jesuitasy en el Seminario Conciliar; otros, como Peza, pudieron estrenar la Escuela Nacional Preparatoria, baluarte positivista ideado por Barreda en la postrimería de 1867. Debido a tales circunstancias formativas, el elenco de poetas apuntó, como el grueso de sus coetáneos, hacia una disposición "posreformista, posromántica, in- 
telectual, urbana, clasemediera con tufos aristocráticos, mestiza, cientifizante, modernizadora, universitaria, oradora, política”, según el razonable sumario de Fernando Curiel (2001: 57) basado en la caracterización que Luis González y González formuló para la Generación de los Científicos, en La ronda de las generaciones (1984: 37-51).

$\mathrm{Al}$ cotejar aquellas particularidades con el caso de Manuel Acuña, cabecilla del grupo, es posible observar las coincidencias: el poeta, norteńo, había llegado a la capital del país en 1865 con la finalidad de concluir los estudios necesarios para matricularse en la Escuela de Medicina. A partir de su arribo se dejó ver la traza urbana de sus composiciones poéticas, más animadas por el liberalismo ateo de Ignacio Ramírez que por las enseñanzas religiosas que pudo abrevar en Saltillo. Estudiante universitario, de haber vivido más, acaso habría tenido oportunidades en la diplomacia, como Juan de Dios Peza, integrante de la legación mexicana en España; o en la política, como el diputado Francisco G. Cosmes; seguramente habría continuado, por lo menos durante algún tiempo, en la senda periodística, como Agustín F. Cuenca. La suya era una generación intelectual, urbana, clasemediera, universitaria, e incluso posromántica, pues, aunque Acuña fue un célebre representante del Romanticismo, debe recordarse que falleció precisamente cuando la renovación estética se atizbaba en el horizonte lírico, de la mano de su amigo Cuenca (Pacheco, 1999: 31).

Al clasificar las generaciones literarias mexicanas, González y González y Curiel Defossé, colocan a Acuña, Cuenca y Peza, como integrantes de la generación de los Científicos. A su lado sitúan a los personajes erigidos en minoría rectora en el cenit y ocaso del Porfiriato, nacidos alrededor de la década del cincuenta del siglo XIX, cuya aparición en la escena pública ocurrió hacia la década del setenta de la misma centuria; tal es el caso de la Sociedad Nezahualcóyotl, como se recordará. El inventario establecido por don 
Luis González y González incluye treinta y tres políticos, treinta y nueve intelectuales, siete sacerdotes, diez militares y diez empresarios (1984: 114-116). Entre los intelectuales, destacan Acuña, Cuenca y Peza, según se indicó. Esto resulta significativo para la historia literaria, pues los dos primeros murieron antes de tener tiempo para valorar desde la distancia su trabajo en equipo: Manuel se despidió del mundo brindando con cianuro en 1873, en tanto Agustín sucumbió dolorosamente a la hepatitis en 1884; en consecuencia, ninguno logró hacer el recorrido hasta el cenit y ocaso porfirianos. Peza sí: falleció en 1910, después de haber sido miembro numerario de la Academia Mexicana de la Lengua y haber trabajado como diplomático, diputado y periodista.

Juan de Dios, historiador lírico del grupo, anotó en 1877: "Formo parte, aunque última, de esa falange que tuvo por caudillo a Manuel Acuña" (Peza, 1965: 9). Dos palabras brillan en esa frase: falange y caudillo. La conciencia de formar parte de una colectividad, así como la designación de un líder de la misma, revelan la elección de un itinerario compartido: además de los proyectos personales (ya estéticos, ya políticos), hubo ahí proyectos grupales; a la coincidencia de edades se añadió la convergencia en la búsqueda intelectual. Los propósitos unificadores quedaron registrados con suma claridad en las siguientes líneas:

Había por los años de 67 a 68, un grupo de estudiantes pobres, que sin más afán que la conquista de un nombre en la república de las letras, se unían para estudiar y cultivar el divino arte de la poesía. Allí estaban [Manuel] Acuña, [Agustín] Cuenca, Francisco Ortiz, [Pablo] Sandoval, [Francisco] Cosmes, Gerardo M. Silva, [Antonio] Domínguez [Salazar], Rafael Rebollar, Javier Santa María, Alfredo Higareda, Miguel Portillo y otros de los que ahora gozan de justa estimación en nuestros círculos ilustrados. Este grupo formaba la Sociedad Nezahualcóyotl, presidida, cuando yo la conocí, por Ricardo Ramírez, hijo del reputado "Nigro- 
mante" [Ignacio Ramírez]. Aquella sociedad estudiosa, entusiasta y juvenil, trataba en sus sesiones, de los más graves asuntos que preocupan a eminentes literatos. Se buscaba la manera de tener literatura propia, de reformar nuestro teatro, de impulsar nuestras publicaciones, de comunicarnos con todos los hombres de letras de la América del Sur, en una palabra, de todo eso que forma la sólida base del progreso literario en un pueblo culto y razonador (Peza, 1965: 27; cursivas mías).

Son palabras del antedicho historiador lírico. Es probable que al anotarlas tuviera frente a sus ojos, memorioso, el prólogo de un volumen impreso por don Ignacio Escalante en 1869, con el título Ensayos literarios de la Sociedad Nezahualcóyotl. En el prólogo, suerte de manifiesto firmado en mayo de ese año por "Los miembros" de la Sociedad, se apuntó:

Nos atrevemos a presentar al público esta colección de composiciones poéticas y en prosa, demasiado humildes para que puedan ser acreedoras al nombre de piezas literarias. [...] Al darlas a luz, no hacemos otra cosa sino seguir el movimiento general que se verifica hoy en el mundo de las letras: contribuir con nuestro pequeńo contingente; agregar nuestro imperceptible grano de arena a la base del suntuosos monumento literario que otros están llamados a construir. [...] Por lo demás, ¿qué deseos ambiciosos pueden tener unos estudiantes que se congregan con el exclusivo objeto de leerse mutuamente composiciones ligeras, fruto de sus ratos de ocio, o de aquellos que pueden robar a sus severas ocupaciones de colegio? ¿Qué aspiraciones innobles han de animar a un grupo de jóvenes que se asocian familiarmente con el fin de derramar el aroma de sus corazones en el seno de una amistad fraternal? (Ensayos, 1869: 3-4)

Se trataba de jóvenes nacidos y desarrollados en un clima nacional de guerra continua, librada a veces contra invasores extranjeros 
y a veces entre las facciones oriundas. Este hecho histórico compartido repercutió en uno de los temas medulares de la obra que pronto iniciarían: la ineludible reconstrucción del país, tras el cese de la guerra y el triunfo liberal. En esas condiciones, concibieron la literatura como un espacio adecuado para dar cuenta de lo esencialmente mexicano, aquello por lo que se había luchado desde la revolución de Independencia. Para lograrlo, encontraron útil aprovechar tanto el teatro como las publicaciones poéticas a manera de vehículos de ideas. Además, el sesgo programático del prólogo incluía la formación de redes con colegas sudamericanos: jóvenes también, radicados en países cuyos movimientos independentistas estaban rindiendo sus frutos en la segunda mitad de la centuria. Todo ello, en nombre del "progreso literario en un pueblo culto y razonador" (Peza, 1965: 27).

Aquella presentación de trabajos poéticos, parapetada tras la retórica de la humildad, fue antecedida por la publicación de algunas composiciones de los miembros del grupo en el periódico La Iberia, dirigido por Anselmo de la Portilla. Pronto se sumó a esas actividades la fundación de El Anáhuac, revista de la Sociedad, que comenzó a circular a mediados de 1869 ("Nuevo periódico", 1869: 3), prologada por un político liberal y destacado escritor romántico: Manuel Payno (igualmente colaborador de Ensayos literarios). También contaron con el apoyo de Ignacio Ramírez ("mi maestro y el prologuista de mis versos”, detalló uno de los jóvenes), cuyo hijo, según se indicó con anterioridad, presidió alguna vez la Sociedad Nezahualcóyotl (Peza, 1965: 21). Otro estímulo político temprano vino del director del Instituto Científico y Literario de Toluca (alma mater de Altamirano y espacio de trabajo docente de Ignacio Ramírez), el licenciado Felipe Sánchez Solís, quien abrió las puertas de su casa particular para que el grupo celebrara el primer aniversario de su fundación, en abril de 1869. Pero con seguridad fue el padrinazgo de Ignacio Manuel Altamirano, autor de 
dos composiciones incluidas en Ensayos literarios, lo que fortificó la celebridad de esos discípulos a quienes el abogado guerrerense reconoció como colegas: son "bohemios como nosotros”, escribió (Altamirano, 1979b: 162).

Había en los poderosos mentores la convicción de estar ante un grupo "compuesto en su mayor parte de jóvenes aficionados a las bellas letras", en quienes vieron "una prueba más del movimiento literario que se está verificando en este país desde hace algunos meses" ("Sociedad literaria", 1869). Habrá que insistir en que éste era un movimiento protagonizado por ilustres caballeros de letras, "la constelación fulgurante de nuestro cielo literario" (Ensayos, 1869: 4), pero también por jóvenes que se presentaban ante el "público modestamente y sin pretensiones, declarando, por el contrario, que [acogerían] con gusto las advertencias y los consejos de la crítica" ("Bibliografía", 1869: 3). Así pues, en mayo de 1869 comenzaron a circular bajo el abrigo de un influyente padrinazgo los Ensayos literarios, en el espacio destinado al folletín de La Iberia ("Ensayos", 1869: 3). Todavía un año después, el libro se ofrecía a un peso con veinticinco centavos en las oficinas del diario ("Libros de venta en el despacho de La Iberia", 1870: 4).

\section{De juaristas a porfiristas: discípulos serenos}

Peza confesó con orgullo que Altamirano resultó decisivo, "contribuyendo a popularizarlos en los más altos círculos de los hombres de letras, y prestándoles toda su influencia poderosa cuando les inició en la vida pública"; también admitió la existencia de cierta jerarquía: "todos los jóvenes escritores le llaman maestro" (1965: 21; 1990: 153). En prenda de su amparo, en El Renacimiento (1869), revista mediante la cual tras la guerra se buscó una reconciliación entre liberales y conservadores, el Maestro publicó tres poemas de 
Acuña y dos de Higareda; en tanto Cuenca, Domínguez y Rebollar, colaboraron respectivamente con uno.

Altamirano descubrió su potencial y los protegió. También les mostró el camino del nacionalismo liberal. Al acercarse el final de la década del sesenta, el Maestro los presentó como una "nueva generación literaria" (2002: 22), y simbólicamente los asoció con el año 1867. La fecha, se comprende, está lejos de ser caprichosa. Corresponde a la caída de Maximiliano y el consiguiente regreso de Benito Juárez a la capital del país para instaurar el Estado republicano: el vínculo entre realidad política y expresión literaria, en el pensamiento estético altamiraniano, resultó ostensible. "La bella literatura tiene fervientes partidarios en la República", advirtió entusiasta (Altamirano, 2002: 29), observando una renovación de las filas letradas al tiempo que el esquema político se tornaba ideario poético. A un nuevo país, correspondía una nueva forma de entender la literatura.

Hay otro asunto a destacar en la identificación de una cosmovisión compartida por los jóvenes bardos: su abierta simpatía por las ideas laicas de sus remotos inspiradores, los enciclopedistas franceses. Para nadie era sorpresa la militancia de los nuevos escritores y de sus maestros en el partido liberal. Más aún, entre las diversas asociaciones a las cuales pertenecieron, estuvo precisamente la Sociedad de Libres Pensadores [sic] (1870-1871), la cual contó entre sus miembros a Acuña, Altamirano, Cuenca, Joaquín Baranda, Gustavo Baz, Francisco Bulnes, Luis Gonzaga Ortiz, Gustavo Gosdawa barón de Gosthowski, además de Justo y Santiago Sierra (Perales, 2000: 120). Además, resultaron celebres las polémicas desatadas, primero, por los poemas racionalistas de Acuña, tachados de ateos por el periódico La Sociedad Católica; y, después, por la ceremonia luctuosa en honor de ese mismo joven, en diciembre de 1873. En esa ocasión, los redactores de $\mathrm{La}$ Voz de México, diario católico, consideraron las exequias "una manifesta- 
ción política, anti-religiosa-literaria”, e iniciaron una provocadora discusión moral sobre el suicidio de Acuña (Caffarel, 1999: 14). La Generación de 1867, en resumen, incluyó un novedoso y marcado componente anticlerical ya presente en sus maestros.

Aquí es conveniente hacer un alto para destacar tres asuntos. El primero consiste en que la renovación estuvo lejos de ser sólo literaria - hecho demostrado con amplitud por Luis González en La ronda de las generaciones-; el segundo reside en el pacífico traspaso de poder de una generación a otra. José Ortega y Gasset mostró en su momento la existencia de generaciones acumulativas y generaciones revolucionarias; pues bien, en México, los Científicos optaron por lo primero al seguir las enseñanzas éticas y estéticas de sus mentores. Fernando Tola ha indicado con razón que los integrantes de "la propia generación [del Renacimiento] asumen plácidamente el papel de discípulos declarados y rodean de admiración a los maestros" (2005: 218). Por lo demás, resultaría excesivo afirmar con Luis González y González que "se caracterizaron por sus modales de sumisión, por su obediencia ciega a lecciones, usos, costumbres y modas" (1984: 40). Hay que matizar estas palabras, sobre todo si recordamos, entre otros, los nombres de Laureana Wrigth y Laura Méndez; ambas, periodistas aguerridas, precursoras feministas, editoras, poetas, ensayistas, críticas incansables de los usos y costumbres más retrógrados del país. Dicho de otra forma, el tránsito generacional habrá sido sosegado, pero no careció de gratas sorpresas, como la aparición de un gran grupo de escritoras.

El tercer asunto a destacar se relaciona con las denominaciones de la generación que nos ocupa. Los integrantes de la Sociedad Nezahualcóyotl, como se ha advertido, fueron la expresión literaria de la Generación de los Científicos. Ello es patente en poemas positivistas como "Ante un cadáver", de Manuel Acuña; en la confianza de Laura Méndez y Justo Sierra en la educación 
como fuerza transformadora; en el volumen El verdadero Bulnes y su falso Juárez (Talleres de Tipografía, Encuadernación y Rayados, 1904), de Francisco G. Cosmes, convertido en historiador durante su madurez. Y los nexos se extienden hasta el terreno de la administración pública, donde Peza y los mencionados Méndez y Sierra trabajaron para el gobierno porfirista. Así, varios de los optimistas muchachos juaristas de la Generación de 1867 se convirtieron, en su etapa madura, en los hombres y mujeres que apuntalaron el gobierno de Porfirio Díaz bajo la pauta "científica".

\section{El elenco: nacionalistas bohemios y gregarios}

En armonía con las ideas sobre la responsabilidad de los letrados con su patria, algunos Científicos practicaron la docencia y el periodismo; otros siguieron el camino de la política, no obstante que esa pléyade "jamás [ejerció] en plenitud el mando político, que sí el económico y el cultural” (González y González, 1984: 46). La abogacía fue, en todo caso, la profesión más favorecida por ellos. Esto se tradujo en la aspiración a puestos en la administración pública: Justo Sierra Méndez fue ministro de Instrucción Pública y Bellas Artes; José Ives Limantour, ministro de Hacienda; Bernardo Reyes, ministro de Guerra; poetas como Agapito Silva, Manuel M. Flores, Manuel José Othón y narradores como Ireneo Paz, entre tantos otros, fueron diputados. Agustín F. Cuenca fue edil en el ayuntamiento de Orizaba, Veracruz, en tanto José López Portillo y Rojas consiguió la gubernatura de Jalisco, su estado natal.

En líneas anteriores se han mencionado varios nombres para tratar de reconstruir el elenco total de la Generación de 1867. Inicialmente, los referidos por Peza en su comentario de 1877; después, los incorporados por don Luis González en su trabajo revisionista. Pues bien, el elenco total abarca varios círculos, como el correspondiente a la Sociedad Nezahualcóyotl y otros colabora- 
dores de la revista El Renacimiento, o el formado por el equipo de Científicos de José Ives Limantour en el gabinete de Porfirio Díaz. A pesar de pertenecer a esferas sociales y económicas diferentes, hubo entre ellos circunstancias de nacimiento, desarrollo y desenlace, muy similares.

Con todo, si hemos de atender con mayor especificidad el terreno intelectual, será de utilidad echar otro vistazo a la opinión del maestro Altamirano, pionero en la detección de aquél nuevo modo de entender las letras, la política y el país. En el examen que publicó en su "Revista literaria y bibliográfica" en la década de 1880, no se limitó a enlistar a los muchachos que se reunían en el ex Convento de San Jerónimo. En su inventario admitió, desde luego, a Manuel Acuña (ya muerto: "cortó su porvenir por el suicidio que aumentó su celebridad ya grande"), pero también a Ignacio Aguilar y Marocho, Anselmo Alfaro, Gustavo Baz (quien desempeñaba "la secretaría de la Legación Mexicana en Madrid"), Jerónimo Baturoni, Manuel Caballero, Fernando Calderón, Roberto Casellas Rivas, Pedro Castera, Rafael B. de la Colina, Nicanor Contreras Elizalde, Francisco Cosmes, Agustín Cuenca ("consagrado hoy al periodismo"), José de J. Cuevas, Salvador Díaz Mirón, Manuel M. Flores, Francisco Gómez Flores, Manuel Gutiérrez Nájera, J. Hammecken y Mexía, Luis G. Iza, Francisco A. Lerdo, Vicente Morales, José Monroy, Manuel Olaguíbel (“entregado a la judicatura”), Francisco Ortiz, Manuel J. Othón, Ireneo Paz, José Peón Contreras, Manuel Peredo, Juan de Dios Peza, Antonio Plaza (muerto "en la miseria"), José M. Ramírez, Ramón Rodríguez Rivera (cuya musa había "enmudecido ahogada de súbito en el torbellino de las cosas públicas"), José Rosas Moreno, Juan B. Rousset, Javier Santa María, Justo Sierra, Francisco Sosa, Juan Valle, Antonio Zaragoza, Julio Zárate y Rafael de Zayas Enríquez. Obsérvese la cantidad de deserciones (forzosas o no) y sus motivos. 
Menos apegado emocionalmente a aquella generación, hacia el final del siglo el jalisciense Manuel Puga y Acal sostuvo que entre 1880 y 1910 podía situarse la etapa de formación de la "verdadera lírica nacional" (1999: 158), la cual, desde su punto de vista, no era precisamente la alimentada por los alumnos de Altamirano. Por lo menos no en una primera instancia. Para ilustrar su dicho, enlistó tres sacerdotes poetas (Joaquín Arcadio Pagaza, Ignacio Montes de Oca y Federico Escobedo), un traductor de líricos latinos (Joaquín D. Casasús), "poetas excelentes” (Manuel José Othón, Laura Méndez de Cuenca y Manuel M. González); finalmente, añadió a personas nacidas entre las décadas de 1850 y 1870: Sierra, Gutiérrez Nájera, López Portillo y Rojas, Díaz Mirón, Antonio Zaragoza, José M. Bustillos, Francisco A. de Icaza, Luis G. Urbina, Adalberto Esteva, José Peón del Valle, Celedonio Junco de la Vega, José I. Novelo, Luis Rosado Vega, Manuel Caballero, Juan B. Delgado, María Enriqueta Camarillo de Pereyra. En otra etapa colocó a José Juan Tablada, Balbino Dávalos, Amado Nervo, Francisco M. de Olaguíbel, Díaz Mirón (en su segunda época), Manuel de la Parra, Enrique González Martínez, Jesús E. Valenzuela y Rafael López. Como se ve, Puga y Acal situó los alcances del proyecto literario nacionalista en terrenos propios de lo que Luis González ha denominado la "centuria azul": la del Modernismo, la del propio Puga y Acal, quien de esa forma hilvanó su genealogía literaria.

En 1917, otro modernista recordó a "los discípulos de Alamirano”. En su opinión, éstos pertenecieron a dos promociones: la primera sería la de Sierra, Joaquín D. Casasús, Peza, “y muy niño, escolarillo travieso, Manuel Gutiérrez Nájera” (Urbina, 1986: 134); en la segunda anotó a José María Bustillos, Balvino Dávalos, Enrique Fernández Granados, Antonio de la Peña y Reyes, Rafael de Alba y Ángel de Campo. También mencionó, sin lograr situarlos con precisión, a Cuenca, Díaz Mirón y Othón. 
Un cotejo de las listas suma alrededor de seis decenas de nombres. Algunos, reiterados por todos; nadie duda de la presencia de Manuel Acuña y de su liderazgo, por ejemplo. Otros están ausentes en la mayoría de los recuentos, pese a ser coetáneos del círculo principal y pese a las múltiples evidencias de sus nexos ideológicos, políticos, laborales, personales y estéticos, tanto con los protagonistas como con sus mentores; tal es el caso de Laura Méndez, de quien Acuña fue compañero sentimental. Los criterios de inserción parecen a momentos más dictados por la amistad (como en Peza) o por el deseo de articular un contexto idóneo para acicalar la autobiografía (como en Puga y Acal), que por la trascendencia de las obras de los escritores a quienes se menciona: muchos de los amigos de Acuña, Cuenca y Peza, jamás alcanzaron el privilegio de aparecer en nuestros libros de historia literaria, pero brillan en la lista del último.

El propio líder de la Generación de 1867 publicó poco entre dos pastas. Hay once poemas y un artículo de su autoría en Ensayos literarios de la Sociedad Nezahualcóyotl (1869), algunos poemas coleccionados en Lira de la juventud por Juan E. Barbero (Imp. de la Bohemia Literaria, 1872), La gloria. Pequeño poema en dos cantos (La Nación, Valle Hnos., impresores, 1873), y una cartaprólogo a la novela de Vicente Morales, Gerardo. Historia de un jugador (Imp. de Ignacio Cumplido, 1874), distribuida poco después del suicidio del vate, cuya poesía fue recogida en un volumen post mortem. Lo mismo ocurió con la de Cuenca, quien sólo alcanzó a ver la edición del folleto Para besarla (Imp. de Ignacio Cumplido, 1875), el drama La cadena de hierro (Orizaba: Imp. G.G. Guapillo, 1881) y Ángela Peralta de Castera. Rasgos biográficos (Valle Hermanos, 1873). Los poemas de los otros muchachos se antologaron en repertorios como El Parnaso Mexicano, serie de cuadernillos donde se publicó algo de Javier Santa María, Agapito 
Silva, Rafael Rebollar, Alfredo Higareda, Francisco Ortiz, Juan de Dios Peza, Francisco G. Cosmes y, por supuesto, Acuña y Cuenca.

En su mayoría, esos escritores pertenecieron por lo menos a una de las asociaciones que Alicia Perales Ojeda ha denominado "de la corriente literaria del nacionalismo"; a saber: Liceo Mexicano, las veladas literarias de 1867-1868, La Bohemia Literaria, la Sociedad Lateriana, la Nezahualcóyotl, el grupo de El Renacimiento, la Sociedad Católica, la de Libres Pensadores [sic] y la Artístico Industrial, la Academia Nacional de Ciencias y Literatura, la Asociación Dramática, La Estrella del Porvenir, las reuniones en casa de Rosario de la Peńa, el Liceo Hidalgo, la Sociedad Científica, Artística y Literaria El Porvenir, la Sociedad Literaria La Concordia, la Sociedad Dramática Alianza, la Academia Mexicana de la Lengua, la Sociedad Artística de Declamación, El Ramillete de Flores, la Sociedad Mutualista de Escritores, La Esperanza, el Liceo del Porvenir, la Sociedad de Escritores Dramáticos Manuel Eduardo de Gorostiza, la Alarcón, la Peón Contreras, la de Escritores, el Círculo Gustavo Adolfo Bécquer, la Sociedad Dramática Carlos Escudero, la Internacional de Ciencias y Literatura, la Juan Díaz Covarrubias, la Dramática Enrique Guasp de Peris, la Luis Zárate, la Juárez, la Literaria Fernando Calderón, la Dramática Mexicana, la Apolo, la Dramática Literaria Julián Romero, las asociaciones Literaria Internacional y de Periodistas, el Ateneo Mexicano de Ciencias y Artes y el Liceo Morelos. En suma, formaron parte de muchos "grupos de coyuntura" (Curiel, 2008: 288), interesados en dar vida a las letras del país cuando éste, por fin, pudo vivir en paz después de décadas de guerra.

\section{El desenlace marcado por dos revoluciones}

Otra de las peculiaridades de la Generación de 1867 es la temprana desaparición de varios de sus miembros. Ciertamente las ausen- 
cias confieren un tono nostálgico a las memorias de Peza, quien evocó una publicación antigua (La lira de la juventud, 1872) y encontró que nueve años después de editada, habían muerto trece de un total de treinta y seis colaboradores, "soñadores muy jóvenes entonces” (Peza, 1990: 140): Acuña, Cuenca, Agustín V. Bonequi, Martín Fernández de Jáuregui, Francisco P. Guzmán, Francisco de A. Lerdo, Severino Mercado, José Negrete, José Vicente Omańa, Ramón Rodríguez Rivera, Manuel María Romero, Santiago Sierra y Rodolfo Talavera. El libro aquel era un cementerio.

Unos murieron y otros "dejaron la lira" o cedieron ante el paulatino "enmudecimiento de la musa", según expresiones de Altamirano. El periodismo y la política fueron factores decisivos para que los poetas olvidaran sus composiciones entre las amarillentas páginas de revistas, periódicos y libros inaugurales. Jesús E. Valenzuela, desde su posición de miembro de una generación revolucionaria con pretensiones parricidas, lo resumió así:

Frustrada la obra de Acuña, muertos Cuenca y Manuel Flores, aislado Díaz Mirón en su roca cercada por las ondas líricas, retirado Justo Sierra a estudios serios y trascendentales, endomingado Juan de Dios Peza en crónicas-romances, dormido Othón en cualquier bosque potosino, en medio de un desastre clásico-romántico-becqueriano, sólo Gutiérrez Nájera, con un instinto artístico incomparable, cultivaba la nueva cepa (Valenzuela, 2001: 117-118).

La jubilación (Luis González dixit) llegó a los Científicos de la mano de la estirpe modernista; otro tanto hizo para desvanecerlos la Revolución Mexicana. Precisamente en el emblemático año de 1910 murió Juan de Dios Peza, "un resto de la vieja escuela", en opinión el miembro de la "generación azul" citado con anterioridad (Valenzuela, 2001: 141). En ese mismo año, Laura Méndez, integrante extraoficial de la Generación de 1867, fue considerada por los ateneístas como una "delegada de otra edad poética” (Re- 
yes, 2000: 206). El cambio generacional era un hecho. La nueva camada reconoció la existencia de la previa al rebatir sus principios fundamentales; positivismo, nacionalismo y otras palabras caras a los muchachos de la Sociedad Nezahualcóyotl, habían perdido vigencia en el nuevo vocabulario de la ciudad letrada.

¿Sus aspiraciones éticas y estéticas se cumplieron en el terreno textual? No del todo, pero queda para otro momento el análisis de esa literatura surgida al abrigo de un optimismo comprensible: era propia de un país que necesitaba definirse y confiaba en sus jóvenes intelectuales para lograrlo.

\section{Bibliografía}

Altamirano, Ignacio Manuel, 1979a., "Crónica de la semana”, en El Renacimiento. Periódico literario, edición facsimilar, t. II, (11 de septiembre de 1869), México, Universidad Nacional Autónoma de México, pp. 17-20.

, 1979b, "Crónica de la semana”, en El Renacimiento. Periódico literario, edición facsimilar, t. II, (13 de noviembre de 1869), México, Universidad Nacional Autónoma de México, pp. 161-163.

, 2002, "Revista literaria y bibliográfica” en La literatura nacional, t. II. José Luis Martínez (ed. y pról.), México, Porrúa (Escritores Mexicanos, 53), pp. 21-29.

Caffarel Peralta, Pedro, 1999, El verdadero Manuel Acuña, México, Universidad Nacional Autónoma de México, (Al siglo XIX. Ida y regreso).

Clark de Lara, Belem, 2005, “'Generaciones o constelaciones?”, La República de las Letras. Asomos a la cultura escrita del México decimonónico, vol. I, Ambientes, asociaciones y grupos. Movimientos, temas y géneros literarios, Belem Clark de Lara y Elisa Speckman Guerra (ed. y estudio intro.), México, Universidad 
Nacional Autónoma de México (Al siglo XIX. Ida y regreso), pp. 11-46.

Curiel Defossé, Fernando, 2001, Elementos para un esquema generacional aplicable a cien años (aprox.) de literatura patria, México, Instituto de Investigaciones Filológicas-Universidad Nacional Autónoma de México (Colección de bolsillo, 18).

, 2008,Sigloveinte@lit.mx.Amplio tratado de perspectiva generacional, México, Universidad Nacional Autónoma de México.

Ensayos literarios de la Sociedad Nezahualcóyotl, 1869, México, Imprenta de Ignacio Escalante y Cía.

García Cubas, Antonio, 1904, El libro de mis recuerdos, México: Imprenta de Arturo García Cubas, Hermanos Sucesores.

González, Luis, 1984. La ronda de las generaciones. Los protagonistas de la Reforma y la Revolución Mexicana, México, Secretaría de Educación Pública.

Pacheco, José Emilio (intro., sel. y notas), 1999, Antología del Modernismo (1884-1921), México, Universidad Nacional Autónoma de México / Ediciones Era (Biblioteca del Estudiante Universitario 90-91).

Perales Ojeda, Alicia, 2000, Las asociaciones literarias mexicanas, México, Universidad Nacional Autónoma de México (Al siglo XIX. Ida y regreso).

Peza, Juan de Dios, 1965, Poetas y escritores modernos mexicanos, Andrés Henestrosa (ed., pról. y notas), México, Secretaría de Educación Pública (Ediciones de El libro y el pueblo).

, 1990, Memorias, reliquias y retratos, Isabel Quiñónez (pról.), México, Porrúa ("Sepan cuantos...”, 594).

Puga y Acal, Manuel, 1999, Los poetas mexicanos contemporáneos, Eugenia Revueltas (pres.), México, Universidad Nacional Autónoma de México (Al siglo XIX. Ida y regreso). 
Reyes, Alfonso, 2000, Pasado inmediato, en Conferencias del Ateneo de la Juventud, Juan Hernández Luna (pról., notas y recopilación de apéndices), Seguido de Anejo documental de Fernando Curiel Deffosé, México, Universidad Nacional Autónoma de México.

Tola de Habich, Fernando, "Propuesta para una periodización generacional de la literatura mexicana del siglo XIX", La República de las Letras. Asomos a la cultura escrita del México decimonónico, vol. I. Ambientes, asociaciones y grupos. Movimientos, temas y géneros literarios, Belem Clark de Lara y Elisa Speckman Guerra (ed. y estudio intro.), México, Universidad Nacional Autónoma de México (Al siglo XIX. Ida y regreso), pp. 203-220.

Urbina, Luis G., 1986, La vida literaria de México y La literatura mexicana durante la guerra de la Independencia, $3^{a}$ ed., Antonio Castro Leal (ed. y pról.), México, Porrúa (Colección de Escritores Mexicanos, 27).

Valenzuela, Jesús E., 2001, Mis recuerdos, Vicente Quirarte (pról., ed. y notas), México, Conaculta (Memorias Mexicanas).

\section{Hemerografía}

"Bibliografía", 1869, El Siglo Diecinueve, sétima [sic] época, año XXVI, t. VII, núm. 147 (27 de mayo), p. 3.

Cuenca, Agustín F, 1874, "Manuel Acuña", El Siglo Diecinueve, octava época, año XXXIII, t. 66, núm. 10, 891 (5 de diciembre), p. 3.

"Ensayos literarios", 1869, La Iberia, t. V, núm. 658 (26 de mayo), p. 3.

"Libros de venta en el despacho de La Iberia", 1870, La Iberia, t. VI, núm. 952 (8 de mayo), p. 4. 
"Nuevo periódico", 1869, El Siglo Diecinueve, sétima [sic] época, ańo XXVI, tomo sétimo [sic], núm. 246 (3 de septiembre), p. 3.

Peza, Juan de Dios, 1894. "Flor de luna. Poema de Manuel Larrañaga Portugal. Prólogo de Juan de Dios Peza”, Revista Azul, tomo I, núm. 12 (22 de julio), pp. 182-186.

"Sociedad literaria de Nezahualcóyotl", 1869, La Iberia, tomo V, núm. 559 (29 de enero), p. 3.

(Artículo recibido el 28 de julio de 2013; aceptado el 29 de octubre de 2013). 